\title{
ATIVIDADE DOCENTE EM CENA: O FOCO NO ATENDIMENTO EDUCACIONAL ESPECIALIZADO (AEE) PARA EDUCANDOS COM TRANSTORNO DO ESPECTRO AUTISTA (TEA)
}

\author{
TEACHING ACTIVITY IN SCENE: FOCUS ON SPECIALIZED EDUCATIONAL \\ SERVICE (SES) FOR LEARNERS WITH AUTISTA SPECTRUM DISORDER (ASD) \\ Marily Oliveira Barbosa ${ }^{1}$ \\ Neiza de Lourdes Frederico Fumes ${ }^{2}$
}

\begin{abstract}
Resumo
O objetivo deste artigo é analisar a concepção docente sobre o Atendimento Educacional Especializado (AEE) oferecido aos educandos com Transtorno do Espectro Autista (TEA). Foi realizado um estudo qualitativo, no qual participou uma professora do AEE e seus três alunos com TEA matriculados na rede regular de ensino. Para a coleta de dados foram realizadas: análise documental; observação com videogravação; entrevistas; e autoconfrontação simples. Os dados foram analisados por meio da análise de conteúdo. Como resultados, constatou-se a concepção da escola como ambiente acolhedor, que buscava a inclusão de educandos. Verificou-se a inexistência de regras ou fórmulas para lidar com estes educandos, visto a diversidade no transtorno. Em relação ao AEE, este era um dos pilares para que a discussão da inclusão escolar acontecesse na instituição. Considera-se, assim, a necessidade de novas pesquisas, visto que a temática do artigo é relativamente recente e desperta a necessidade de ampliação do conhecimento.
\end{abstract}

Palavras-chave: Educação Especial. Atividade docente. Transtorno do Espectro Autista. Atendimento Educacional Especializado.

\begin{abstract}
The aim of this paper is to analyze the teacher's opinion on the Specialized Educational Service (SES) offered to students with Autistic Spectrum Disorder (ASD). Was developed an qualitative study, in which participated a teacher of the SES and your three students with ASD enrolled in the regular school. To collect were used: documentary analysis; observation with video recording; interviews; and simple self-confrontation. The data were analyzed using content analysis. The results showed a vision about the school as a welcoming environment and aims the inclusion students. It was found that there was no rules or formulas for dealing with these students, due to the diversity in the disorder. About the SES, this was a basis for the discussion of school inclusion happen in school. It is considered, therefore, the need for further research, because the theme of the article is relatively recent and awakens the need to expand knowledge.
\end{abstract}

\footnotetext{
${ }^{1}$ Doutoranda em Educação Especial pela Universidade Federal de São Carlos (UFSCar), MESTRA em Educação pela Universidade Federal de Alagoas (UFAL), GRADUANDA em Pedagogia pela UFAL e Graduada do curso licenciatura em Educação Física pela UFAL. E-mail: marilyufal@ hotmail.com

${ }^{2}$ Doutora e Docente no Programa de Pós-graduação em Educação pela Universidade Federal de Alagoas (UFAL) e coordenadora do Núcleo de Estudos em Educação e Diversidade (NEEDI). E-mail: neizaf@yahoo.com
} 
Keywords: Special education. Teaching activity. Autistic Spectrum Disorder. Specialized Educational Service.

\section{INTRODUÇÃO}

O Transtorno do Espectro Autista (TEA) possui diversas peculiaridades relacionadas ao prejuízo qualitativo nas áreas da interação social, linguagem e movimentos repetitivos e estereotipados. Estes aspectos aparecem de formas diferenciadas nos indivíduos, sendo necessário considerar a individualidade humana e ponderar que cada educando com o transtorno reage de forma diferente (ÓRRU, 2012; APA, 2014).

A expressão Transtorno do Espectro Autista engloba as diversas nuances da condição, mais sem representar uma linha reta com variações entre o leve e o grave. Dessa forma, o termo confirma a heterogeneidade e a amplitude de variações características do TEA e, a APA (2014), agrupam-se em uma única categoria (autismo infantil precoce, autismo infantil, autismo de Kanner, autismo de alto funcionamento, autismo atípico, transtorno global do desenvolvimento sem outra especificação, transtorno desintegrativo da infância e transtorno de Asperger).

Ainda que já tivesse sido anteriormente anunciada em seu sítio oficial ${ }^{3}$, a modificação da nomenclatura foi efetivada com a publicação da quinta versão do Manual diagnóstico e estatísticos de transtornos mentais (APA, 2014). Todavia, alguns estudiosos brasileiros (GOMES, 2011; SCHWARTZMAN, 2011) já utilizavam a nomenclatura TEA antes de sua formalização, bem como a Lei $n^{\circ} 12.764$, de 2012, que instituiu a Política Nacional de Proteção dos Direitos da Pessoa com TEA (BRASIL, 2012).

Em termos de escolarização em contextos inclusivos, o ingresso desses educandos na escola regular é relativamente recente, o que tem trazido novos desafios à escola e aos professores que os recebem. Barbosa e Fumes (2012) afirmam que as escolas públicas da cidade de Maceió registraram um número crescente de matrículas de educandos com TEA em classes comuns e no Atendimento Educacional Especializado. Este fato se configura como um avanço positivo para um grupo que sequer tinha cogitada a possibilidade de matrícula em escola regular. Contudo, não há como garantir que o aumento do número de educando com TEA matriculados seja um reflexo da política da educação especial.

\footnotetext{
3 APA, Associação Americana de Psiquiatria. Autism Spectrum Disorder. 2013. Disponível em: <http://www.dsm5.org/Pages/Default.aspx $>$. Acesso em: 13 de nov.2013.
} 
Para auxiliar a inclusão escolar resultante das matriculas nas escolas regulares, a aprendizagem destas crianças (e outras do público alvo da Educação Especial) e, por conseguinte, sua permanência escolar, o Governo Federal recomendou o AEE, que é "compreendido como o conjunto de atividades, recursos de acessibilidade e pedagógicos organizados institucional e continuamente". (BRASIL, 2011. p. 01).

Afirma-se que este serviço deve ser realizado preferencialmente na Sala de Recursos Multifuncionais (SRM), que caracteriza-se como "ambientes dotados de equipamentos, mobiliários e materiais didáticos e pedagógicos para a oferta do atendimento educacional especializado" (BRASIL, 2011, p. 01), cujo objetivo é contribuir para a inclusão escolar do público alvo da Educação Especial, integrando a proposta pedagógica da escola, com vistas a garantir o acesso, a participação e a aprendizagem desses educandos no ambiente escolar. Tartuci, Silva e Freitas (2013) destacam que, muitas vezes, o profissional da educação especial assume a responsabilidade solitária pelo processo de escolarização dos educandos público alvo da educação especial. Desta forma, o AEE tem por objetivo:

I - prover condições de acesso, participação e aprendizagem no ensino regular e garantir serviços de apoio especializados de acordo com as necessidades individuais dos estudantes; II - garantir a transversalidade das ações da educação especial no ensino regular; III - fomentar o desenvolvimento de recursos didáticos e pedagógicos que eliminem as barreiras no processo de ensino e aprendizagem; e IV - assegurar condições para a continuidade de estudos nos demais níveis, etapas e modalidades de ensino (BRASIL, 2011, p. 02).

Cabe ressaltar que o professor do AEE deve possuir formação inicial na área da docência e específica da Educação Especial (BRASIL, 1996; 2001; 2009), podendo ser realizada de diversas formas, como na formação inicial ou continuada. Tartuci, Silva e Freitas (2013) relatam que essa capacitação acontece, na maioria das vezes, na modalidade à distância, devido às lacunas existentes na graduação. Contudo, Mendes e Malheiro (2012) acreditam que esta formação continuada ainda não é suficiente para o cumprimento das atribuições do professor, em decorrência da sua multiplicidade e que com isso, sua atividade docente pode ser prejudicada.

Cabe salientar que, ao falarmos de atividade docente, apoiamo-nos em $\mathrm{Clot}^{4}$ (2007) que explica que esta prática decorre da conjunção entre a atividade prescrita, a atividade realizada e o real da atividade. Mais especificamente, a atividade prescrita diz respeito à ação

\footnotetext{
${ }^{4}$ Yves Clot estabeleceu um procedimento de pesquisa e de análise que promove a compreensão da correlação entre a atividade e o discurso. Dessa forma, a partir dos conceitos propostos por Vigotski, apresenta a autorreflexão como mediadora do desenvolvimento global da situação de trabalho ( DOUNIS, 2013, p. 94).
} 
executada, que é determinada pelas instâncias maiores, como por exemplo, os dispositivos legais e os encaminhamentos oficiais que direcionam o trabalho do trabalhador (CLOT, 2007). A atividade realizada pode ser entendida como aquilo que pode ser observado aos olhos humanos, ou seja, aquilo que foi implementado, realizado e/ou executado durante a atividade de trabalho, mas que não foi alcançado em sua totalidade.

Já o real da atividade, segundo Clot (2007), é tudo aquilo que ultrapassa a atividade prescrita e a atividade realizada, remetendo-se ao impossível da atividade, sendo, inclusive, aquilo que poderia ou não ter sido feito, aquilo que, ao contrário da atividade realizada, não pode ser visto e observado diretamente. É “[...] aquilo que, mesmo não se concretizando, permeou a atividade real" (DOUNIS, 2013, p. 91).

Diante disso, podemos vislumbrar o quanto a atividade docente pode ser complexa. Desse ponto de vista, a atividade docente vai além do visível e esses aspectos subjetivos precisam ser melhor compreendidos, especialmente quanto ao tema abordado neste estudo.

Diante dessas colocações, este artigo tem como objetivo analisar a atividade docente de uma professora do AEE realizado para educandos com TEA, bem como refletir com essa professora, por meio da autoconfrontação simples, sua atividade realizada.

\section{CAMINHOS METODOLÓGICOS TRILHADOS}

Para esta investigação, utilizou-se a pesquisa de caráter qualitativo. Segundo Flick (2009), os métodos qualitativos consideram a comunicação do pesquisador com o campo e seus membros como parte explícita da produção do conhecimento, caracterizando-se pela interação direta entre o pesquisador e o objeto de estudo. Para a presente investigação, a estratégia de estudo escolhida foi a de estudo de caso, visto que buscamos desvelar um fenômeno contemporâneo de forma aprofundada.

Yin (2010) conceitua o estudo de caso como "uma investigação empírica que investiga um fenômeno contemporâneo em profundidade e em seu contexto de vida real, especialmente quando os limites entre o fenômeno e o contexto não são claramente evidentes" (YIN, 2010, p. 39). Assim, o estudo de caso pode ser um método eficiente, uma vez ele é abrangente e auxilia o pesquisador a chegar ao cerne da questão.

Para selecionar a participante, foi realizado um levantamento na cidade de Maceió a fim de rastrear os alunos com TEA. Foram identificados nove educandos com o diagnóstico de TEA matriculados em cinco Escolas Municipais. De posse dessa informação, foi estabelecido 
em contato com as escolas e com as professoras do AEE, no qual foi obtida aceitação da escola para a participação na pesquisa.

Antes de iniciar a pesquisa, foram realizados os trâmites legais e obtida aprovação do Comitê de Ética da Universidade Federal de Alagoas (UFAL), sob o parecer de $\mathrm{n}^{\circ}$ 206.411/2013.

O caso estudado diz respeito à atividade docente de uma professora do AEE que lecionava para três educandos com TEA. Nesse estudo foram utilizados nomes fictícios para manter o sigilo dos participantes da pesquisa, a saber: professora Diana e educandos Nicolas, Joaquim e Gilvan.

A escolha pela participante ocorreu pelo fato de Diana professora do AEE e por ser considerada pelos seus pares como uma profissional experiente no atendimento a educandos com TEA - atuava havia 12 anos nesta área, tanto na iniciativa privada, como na escola pública. A referida professora possuía dois cursos de especialização (Lato Sensu), tendo participado de vários minicursos e oficinas sobre o TEA. Sua escolha se deu de forma não aleatória, concordando-se com Creswell (2010), de que a escolha intencional dos participantes da pesquisa auxilia o pesquisador a compreender melhor o problema e a questão da pesquisa.

Nicolas tinha 10 anos e, além da escola, frequentava Terapia Ocupacional, Fonoaudiologia e Psicologia. Recebia atendimento no AEE há 2 anos e não possuía auxiliar de sala por ter sido avaliado pela professora Diana e pela professora da sala comum como tendo autonomia suficiente.

Gilvan tinha oito anos e possuía Síndrome de Down com suspeita de TEA. Até o ano de 2012, fez acompanhamentos com profissionais de Fonoaudiologia, Fisioterapia e Terapia Ocupacional, contudo, interrompeu-os devido a uma enfermidade da mãe. O estudante frequentava o AEE e possuía uma auxiliar de sala.

O terceiro educando, Joaquim, tinha sete anos e frequentava os serviços de Terapia Ocupacional, Fonoaudiologia e Psicologia. Também participava de um Centro de Atenção Psicossocial (CAPs), no qual era acompanhado por um neurologista. Joaquim frequentava a escola desde o início de 2012 e, desde então, recebe atendimento no AEE e dispõe de uma auxiliar de sala.

Para a coleta de dados, utilizamos uma variedade de instrumentos, atendendo assim a dinamicidade da pesquisa e buscando obter dados relevantes para a compreensão do problema estudado. Os instrumentos foram: pesquisa documental; observação com apoio em caderno de 
anotações e videogravações dos atendimentos na SRM e de uma palestra proferida pela docente; entrevista semiestruturada e recorrente; e autoconfrontação simples.

As coletas foram realizadas durante dois semestres do ano letivo, totalizando seis meses de imersão da pesquisadora no ambiente da pesquisa. Nesse período, os educandos estavam regularmente matriculados no Ensino Municipal, sendo atendidos individualmente pela professora Diana, em duas sessões semanais, com duração média de 50 minutos. Os educandos frequentavam, respectivamente, o $1^{\circ}, 2^{\circ}$ e $3^{\circ}$ ano do Ensino Fundamental I.

Cabe expor que a autoconfrontação simples se realiza a partir do diálogo e intervenção entre sujeito da pesquisa, pesquisador e imagens. Clot (2007) esclarece que esta ação é direcionada pelo pesquisador e possibilita que o sujeito da pesquisa descreva sua situação de trabalho para alguém que não é ele, a partir da imagem. Esta ação pode desencadear a sua reflexão sobre a ação que visualizou por intermédio dos episódios que foram construídos com fragmentos das observações gravadas das sessões de AEE. Esse instrumento é eficaz na obtenção da reflexão do professor sobre sua atividade docente, pois, à medida que ele se depara com a filmagem da sua prática e com os questionamentos propostos pelo pesquisador, se põe a refletir e a pensar sobre sua atividade de forma única (CLOT, 2007; DOUNIS, 2013).

Neste caso em particular, os episódios selecionados foram aqueles em que a professora teve dificuldades em atuar com educando, seja pela dificuldade da atividade ou pela participação não exitosa do educando, bem como os atendimentos nos quais os objetivos selecionados pela professora foram cumpridos. Após cada episódio, foram feitas algumas perguntas, previamente elaboradas. No decorrer da coleta foram realizadas duas autoconfrontações simples, sendo cada uma composta por três episódios, com intervalo de dois meses entre elas.

Após a coleta dos dados, realizou-se a análise de conteúdo dos materiais produzido. Bardin (2009) expõe que este tipo de análise tem por objetivo descobrir os núcleos de sentido que compõem a comunicação entre pesquisador e sujeito da pesquisa, cuja presença ou frequência de aparição das respostas pode significar alguma coisa para o objeto analítico escolhido. Essa análise desdobra-se em três etapas: pré-análise; exploração do material e tratamento dos resultados obtidos; e interpretação. 


\section{RESULTADOS E ANALISE DOS DADOS}

Nas análises, procurou-se compreender a atividade docente na Sala de Recursos Multifuncionais para educandos com TEA, espaço este em que era desenvolvido o AEE, a partir do ponto de vista da protagonista deste estudo. Segundo Vasques (2008), "a experiência da escolarização envolve uma construção compartilhada a partir dos nossos pressupostos a respeito de escola, aluno, educação, infância etc.” (VASQUES, 2008, p.177). Esses conhecimentos e vivências são responsáveis pela concepção que cada sujeito cria sobre algo e alguém e, além disso, as falas de cada indivíduo estão impregnadas das construções únicas e pessoais.

O AEE, para a professora Diana, é um serviço de atendimento direcionado aos educandos público alvo da educação especial que, quando acontece na escola regular, fomenta e contribui com a consolidação da inclusão escolar. Ao falar sobre ele, a docente remete-se a vários aspectos expostos no Decreto, que regulamenta o AEE (BRASIL, 2011), identificados na fala a seguir:

O AEE é o atendimento educacional especializado. Está dentro daquele projeto de inclusão. É um pedido da educação especial [...] uma coisa só que identifica, elabora e organiza recursos pedagógicos, de acessibilidade. [...]O AEE complementa, suplementa. Ele nunca substitui a sala de aula regular. Aluno nenhum fica só na sala [de recursos multifuncionais]. (FALA PROFERIDA NA PALESTRA).

Neste sentido, constata-se que a professora reproduziu em seu discurso, parte do defendido na Política Nacional de Educação Especial na perspectiva da Educação Inclusiva (BRASIL, 2008), ressaltando que o AEE não deveria substituir o ensino regular.

Essa concepção da professora é defendida também por Cintra, Jesuino e Proença (2010), ao afirmarem que o AEE não deve ser confundido com reforço escolar. Os estudiosos ressaltam que de modo algum o educando deve ir para a SRM para receber um auxílio do que já foi exposto em sala de aula e também, a Política Nacional de Educação Especial na perspectiva da Educação Inclusiva (2008) aponta que o AEE tem o caráter de auxiliar o educando na obtenção de conhecimentos que visem sua autonomia no ambiente escolar. Complementando este posicionamento, a professora Diana esclarece, em outra ocasião, que:

O objetivo da sala de recursos [multifuncionais] é de dar os instrumentos, para que essa criança tenha capacidade. Então o que é que precisa para uma criança aprender (Autoconfrontação 2). 
Este fragmento demonstra que a docente compreendia o AEE conforme as prescrições legais, afirmando que, quando o educando recebe o apoio educacional, se facilita suas condições de acesso, participação e aprendizagem (BRASIL, 2011).

Dentre suas ações, a professora relatou que, além das atividades executadas na SRM, realizava outras fora da sala, como, por exemplo, observar o educando em contexto de sala de aula comum. Sobre isso, Diana explicou que:

A minha ida até a sala de aula [comum] não é muito interferir. Como eu estou atendendo ele duas vezes por semana [Nicolas], eu não estou interferindo tanto em sala de aula, mas eu observo, eu passo. Não é como era antes que eu praticamente ia muito em sala de aula (Autoconfrontação 2)

Durante o período de investigação, por diversas vezes, foi possível visualizar e acompanhar a professora indo até à sala dos educandos, principalmente de Gilvan. Nessas ações, Diana observava de longe os educandos e cumprimentava a turma e a professora (DIÁRIO DE CAMPO, 20/03/2013; 22/05/2013). Ao refletir sobre isso, pode-se ponderar que a professora buscava realizar as atribuições expostas na Resolução $n^{\circ} 4$ (2009): "acompanhar a funcionalidade e a aplicabilidade dos recursos pedagógicos e de acessibilidade na sala de aula comum do ensino regular, bem como em outros ambientes da escola" (BRASIL, 2009), pois as ações realizadas pela professora aconteciam dentro e fora da SRM. Ainda sobre o AEE, Diana declarou que:

Funciona como mediador dos aspectos da aprendizagem dessa criança. Então, a gente trabalha tanto parte dessa comunicação, mas trabalha a parte psicomotora, a parte do aprendizado pedagógico, da memória. Nossas crianças geralmente têm um déficit de atenção, da vinculação. Assim, qual é a maneira que eu faço para que ele se prenda naquilo? Como é que eu trago ele? Então, a gente trabalha fazendo essa mediação, tentando descobrir o que nem mesmo ele se descobriu. Tentamos buscar isso nele (Autoconfrontação 1).

Como mediador da aprendizagem, o AEE funciona como uma estratégia a mais para auxiliar os educandos. Nessa direção, Orrú (2012 considera que o trabalho pedagógico a ser desenvolvido com os educandos com TEA precisa:

[...] contemplar, necessariamente, uma criteriosa relação entre mediação pedagógica, cotidiano e formação de conceitos, possibilitando o encontro/confronto das experiências cotidianas no contexto em que elas ocorrem para a formação de conceitos, quer sejam acadêmicos ou não, em uma maior internalização consciente do que se está sendo vivenciado e concebido. (ORRÚ, 2012, p.102).

O professor precisa se colocar como um mediador, levando em consideração os conhecimentos que o estudante já possui e aqueles que devem ser adquiridos por intermédio 
das atividades propostas, tornando-se, dessa maneira, mediador na construção dos conhecimentos do sujeito. Diana explicou o que entendia por mediação, como consta a seguir:

É você nem fazer por ele, nem deixar que ele não faça, não é? É indicar as setas do caminho que ele pode chegar lá (Autoconfrontação1).

A questão da mediação pedagógica propriamente dita, exposta numa visão histórico cultural, é complexa, contudo, muito importante na formação do conhecimento. Essa mediação acontece por meio da representação do professor como condutor de um processo capaz de favorecer a aprendizagem da criança com TEA, impulsionando o seu desenvolvimento (CHIOTE, 2013). Ainda sobre isso, Orrú (2012) salienta que o ensino é uma ação "repleta de intencionalidade, inferindo nos processos intelectuais, sociais e afetivos do aluno, visando à construção do conhecimento por parte do mesmo, sendo ele o centro do ensino, o sujeito do processo" (ORRÚ, 2012, p.101). Desta maneira, a mediação auxilia o ensino a tornar-se mais acessível ao sujeito.

Afim de compreender a mediação e a atividade docente desenvolvida, é necessário destacar que no AEE havia planos educacionais, os quais foram desenvolvidos de forma individual e eram compostos pelo relatório psicopedagógico do estudante e do plano do AEE. Nos três planos estavam prescritos que as sessões aconteceriam duas vezes por semana, com duração de 50 minutos e de forma coletiva. Os atendimentos possuíam organização semelhante aos AEE de Maceió, com duas sessões semanais em dias alternados (FUMES; OLIVEIRA, 2012).

A análise documental mostrou que os objetivos do plano do AEE para o educando Nicolas eram:

Estimular o processo de autonomia e socialização do aluno; Interceder na integração de Nicolas em sala regular juntamente com seus colegas de sala; Orientar a família de Nicolas a respeito dos novos procedimentos adotados. Desenvolver a melhoria na comunicação, compreensão e expressão de Nicolas; Mediar junto aos professores de sala regular na criação e elaboração de atividades/tarefas onde a participação do aluno seja possível (Plano do AEE- Educando Nicolas).

Notamos que Diana prescreveu trabalhar com aspectos da comunicação e interação social, sendo estes, déficits relacionados ao TEA e, também, que tais objetivos aproximavamse aos definidos pela Resolução n 24/2013 para estes educandos (BRASIL, 2013). Pode-se afirmar que as prescrições que dirigiam a atividade da professora focavam em elementos que poderiam beneficiar o desenvolvimento da aprendizagem e aquisição da autonomia, como verifica-se no enxerto a seguir: 
Introduzir o uso de um sistema de comunicação alternativa. Reorganizar a rotina diária de Nicolas através da elaboração de um painel de gravuras; Realizar juntamente com os professores atividades com a utilização da linguagem de signos contextualizados; Sugerir junto aos professores regulares a explicações das idéias essenciais abordadas nos conteúdos estudados, utilizando recursos de imagens, teatros, cartazes, maquetes; trabalhar com jogos de cartas, memórias e dominó de gravuras estimulando a socialização de Nicolas com seus colegas; introduzir o uso de softwares educativos, estimulando sua memória, concentração e percepção visual (Plano do AEE - Educando Nicolas).

É evidente que o plano proposto para Nicolas está de acordo com a Resolução $\mathrm{n}^{\mathrm{o}}$ 4/2009, que leva em consideração as características individuais dos educandos, bem como, contempla o disposto na Nota Técnica n 24/2013: identificação do educando, as habilidades e necessidades educacionais específicas, a definição e a organização dos serviços e recursos pedagógicos. Contempla, ainda, o tipo de atendimento, a carga horária e a forma de realização individual ou em pequenos grupos (BRASIL, 2009; 2013).

Em se tratando dos planos do AEE para os educandos Joaquim e Gilvan, foi possível constatar semelhanças com o plano anteriormente apresentado, com modificações apenas na identificação dos educandos. Notadamente, a análise revelou que a professora reutilizava o plano para os três educandos mencionados na pesquisa.

É importante salientar que a Nota Técnica $n^{\circ} 24$ dispõe que o planejamento e a organização do AEE devem considerar as características individuais de cada estudante, com a elaboração do plano de atendimento com vistas a eliminar barreiras que dificultem ou impedem a interação social e a comunicação (BRASIL, 2013). Conforme verificou-se, essa orientação não foi seguida nos planos do AEE para Joaquim e Gilvan.

Nesse sentido, cabe dizer que, ainda que os educandos apresentassem características semelhantes, as atividades planejadas não poderiam ser as mesmas e a professora não deveria ter uniformizar os atendimentos, desconsiderando as particularidades dos sujeitos. Diante disso, indagamos a professora Diana, no momento das sessões de autoconfrontação, sobre a construção e efetivação do plano do AEE, cuja resposta encontra-se na sequência:

O plano a gente faz aqui. O plano do AEE é em cima das dificuldades da criança. Não é? A gente não faz esse vínculo com o conteúdo que está sendo dado em sala de aula não. A gente faz em cima da dificuldade que a criança está tendo, porque com que a gente trabalha? Com os instrumentos para que essa criança possa aprender em sala de aula. Possa se desenvolver. Todo o planejamento é pensado só na criança que está sendo feito o plano de atendimento [...] a gente não faz o plano em cima do planejamento pedagógico do professor (Autoconfrontação 2). 
No exposto acima, a professora Diana reafirmou que criava o plano do AEE a partir de suas concepções sobre as necessidades de cada educando. No entanto, observou-se que sua fala não se materializava na prática da atividade prescrita. Outro ponto identificado refere-se ao fato de que o plano do AEE elaborado pela docente não tinha vínculo com o conteúdo da sala de aula, indo contra o estabelecido pelos documentos legais (BRASIL, 2009; 2010; 2013a). Ressalta-se o fato de que a professora acreditava que tal prática estava correta.

Em diversos momentos da pesquisa, a mesma afirmou que seu trabalho era auxiliar na aprendizagem do educando e fomentar a aquisição do conhecimento em sala de aula.

Efetivamente, as ações da docente junto aos educandos Nicolas, Joaquim e Gilvan focavam em atividades psicomotoras realizadas por meio de jogos e atividades psicopedagógicas, os quais estavam em consonância com o plano do AEE, a saber: utilização dos jogos de carta, memória, quebra-cabeça, o uso de softwares educativos, entre outros. Por outro lado, não nos foi possível observar a execução ou realização de atividades que envolviam, por exemplo, o uso de material concreto e fichas de palavras, conto e reconto utilizando fantoches, introdução e/ou uso de um sistema de comunicação alternativa e painel de gravuras, entre outros materiais planejados para o melhor desenvolvimento desses educandos.

Sobre a atividade prescrita e o trabalho realizado, Murta (2008) destaca que muitas vezes o professor enfrenta problemas inesperados, exigindo a modificação do plano ou recriação da sua ação docente. Assim, não há aportes significativos para discutir-se o que de fato foi realizado a partir do que havia sido anteriormente prescrito.

No plano do AEE dos três educados, estava prescrito que a professora iria:

Realizar juntamente com os professores atividades com a utilização da linguagem de signos contextualizados; Sugerir junto aos professores regulares a explicações das idéias essenciais abordadas nos conteúdos estudados, utilizando recursos de imagens, teatros, cartazes, maquetes (PLANO DO AEE- NICOLAS; JOAQUIM; GILVAN).

Essas ações não foram notadas no decorrer da pesquisa, embora estivessem sido prescritas pela docente no plano do AEE dos educandos. A partir do exposto, Diana foi questionada sobre quais atividades desenvolvia com os professores da sala de aula, visto que na proposta que envolve a regulamentação do AEE, compreende-se que este era um serviço de apoio à escolarização do educando, centrado em seu desenvolvimento em sala de aula (MENDES; MALHEIRO, 2012). Nesse sentido, a docente relatou que participava de reuniões com os professores e nelas se informava sobre a aprendizagem dos educandos nos diferentes 
ambientes. No fragmento que se segue, a professora explicou na autoconfrontação simples como estavam organizadas as reuniões na escola:

Na realidade são três reuniões. O planejamento é uma vez por mês. Tem a reunião geral no começo de cada semestre, que é a semana pedagógica e tem o planejamento todo mês (Autoconfrontação 2).

Pode-se inferir que as reuniões ocorriam de forma pontual e muito esparsamente, o que não parece ser suficiente para estabelecer parceria e atuar diretamente com o professor da sala regular, mediante colaboração entre ambos (BRASIL, 2001; 2011). Porém, a professora relatava as dificuldades em estabelecer parcerias com os professores da sala comum, havendo apenas solicitações e cobranças de seus colegas:

\begin{abstract}
A responsabilidade da sala de recursos [multifuncionais] é uma e a do professor da sala de aula é outra. A parte pedagógica e a parte de alfabetizar é dele. Como ele vai fazer isso? Ele tem de buscar. A gente até dá umas dicas para eles, mas as atividades, como é que ele vai fazer, como ele vai inserir a criança nas atividades, ele vai ter que buscar. Eu não posso estar estudando por ele. Eu pesquiso, eu estudo dentro do meu âmbito de trabalho, do meu limite aqui em sala, mas é porque a gente tem isso aqui mesmo. Acho que você até já viu por aqui: "Diana me dá uma atividade para fazer com fulano", "Tem um joguinho aí para eu jogar com o fulano?" A sensação é que o AEE só joga [risos]. "Me dá um joguinho para fazer com fulano". Não é bem assim! Fulano tem que estar adaptado para aquelas atividades (Autoconfrontação 2).
\end{abstract}

Quanto às solicitações das professoras de sala comum, observamos que Diana fazia o que considerava ser necessário e prescrito para a sua função, como dar dicas sobre possíveis ações, auxiliar na resolução de algum conflito envolvendo os educandos atendidos por ela; participar das avaliações dos educandos; e contribuir na flexibilização das avaliações (DIÁRIO DE CAMPO, 03/04/2013; 22/05/2013). Todavia, a docente demonstrou em diversos momentos não acreditar ser sua incumbência entregar as atividades a serem realizadas em sala de aula ou colaborar na superação das dificuldades de alfabetização de sua colega.

De fato, na escola pesquisada não se pode afirmar a existência de parceria entre as professoras do AEE e da sala de aula. Embora trabalhassem no mesmo horário, não havia um momento em que as estas conversassem e trocassem informações, com exceção das reuniões de planejamento citadas anteriormente. Nessa perspectiva, o estudo de Milanesi (2012) aponta que o trabalho da professora do AEE é direcionado cotidianamente ao educando, ficando a parceria com os professores da sala de aula em segundo plano e, consequentemente, 
dificultando as possíveis transformações das práticas pedagógicas destes professores, como recomenda a política da inclusão escolar. Ainda sobre isso, Garcia (2013) expõe que:

Podemos dizer que em grande medida o modi operandi das salas de recursos, do ponto de vista do trabalho docente ali realizado, se mantêm como paralelo ao trabalho realizado na classe comum, o qual pouco incide sobre o processo de escolarização dos sujeitos da modalidade educação especial. (GARCIA, 2013, p.109).

Estes resultados mostram que é necessária a busca de soluções para que esta parceria preconizada aconteça, visto que toda a comunidade escolar só tem a se beneficiar com isso. Não obstante, é preciso levar em consideração que essa realidade é contingenciada por uma série de fatores, entre as quais a falta de um horário em serviço disponível para este encontro, assim como a ausência de interesse mútuo entre as professoras.

Segundo Glat e Pletsch (2012), a atual política de educação inclusiva se insere num ambiente amplo (escola), que possui implicações de ordem estrutural, organizacional, de recursos humanos, entre outros, que, por vezes, não são cogitadas nas diretrizes oficiais. Corroborando com este pensamento, Mendes e Malheiro (2012) afirmam que as diversas funções do professor do AEE reduzem, por vezes, o tempo hábil que este profissional teria para realizar a parceria com o docente da sala de aula. Assim, ao refletir sobre estes aspectos, identifica-se que culpabilizar a professora sobre a ausência desta parceria seria um erro, visto que as dificuldades vão além das características inerentes ao sujeito.

Sobre a atividade que executada com os educandos com TEA, Diana relatou que:

O AEE, ele vê o aluno com autismo numa maneira que você vai criar as coisas para esse aluno com autismo. Nada muito certo. Então, é uma criação o que eu vou fazer com ele. O plano de atendimento do aluno com autismo é completamente diferente. Eu acho que o autismo no AEE é o maior desafio, porque não tem receita nenhuma para a criança com autismo. Então, para mim está em construção (Entrevista semiestruturada).

O AEE para o educando com TEA deve ser realizado de forma complementar, "como apoio permanente e limitado no tempo e na frequência dos estudantes às salas de recursos multifuncionais", conforme o decreto que rege o atendimento (BRASIL, 2011, p.02).

O MEC disponibiliza um fascículo relacionado ao educando com TEA, de autoria de Belisário Filho e Cunha (2010), cuja ênfase é dada aos aspectos conceituais do transtorno, havendo pouca informação e orientação quanto ao AEE voltado para este público. Nele, os autores ressaltam que os educandos devem frequentar o AEE e que o professor necessita contribuir com os demais na elaboração de recursos e rotina escolar. Na obra, está posta a 
necessidade de os educandos utilizarem os recursos pedagógicos e de acessibilidade provenientes da SRM.

No caso analisado, Diana executava atividades de cunho psicopedagógico para seus educandos e o AEE possuía certa rotina, que pôde ser verificada pelas observações, em diário de campo (03/04/2013; 15/05/2013; 22/05/2013). Observa-se, a seguir, um trecho do Diário de Campo que auxiliou na observação da rotina de trabalho mencionada anteriormente.

Ela [Diana] foi buscar Nicolas às $08 \mathrm{~h} 55 \mathrm{~m}$ e terminou às $9 \mathrm{~h} 30 \mathrm{~m}$. Hoje foi trabalhado a
continuação do software Coelho Sabido [utilizado no atendimento anterior
$(08 / 05 / 2013)$ ]. Nicolas realizou bem a atividade, possui conhecimento dos números
(soma) e complementação, inclusive sequência. No jogo com as letras, ele também
realizou a atividade bem, reconhecendo as letras e as iniciais do seu nome. Às $10 \mathrm{hs,}$
Diana pegou o Joaquim e trabalhou com ele o software do coelho sabido (jogo
diferente do utilizado por Nicolas). Terminou às $10 \mathrm{~h} 30 \mathrm{~m}$. O atendimento foi tranquilo
e a saída dele do computador também. Através do software, ele demonstrou
conhecimento das vogais. Diana trabalhou com oralidade e reconhecimento dos
animais, cores e formas. Foi bem satisfatório observar o progresso da fala (Diário de
campo - 15/05/2013).

Todos os atendimentos na SRM envolviam atividades psicopedagógicas. Um exemplo está descrito no Diário de Campo (03/04/2013): “Diana, no início do dia, relatou que iria trabalhar a percepção visual por meio dos aspectos psicomotores com o Nicolas”. Foi buscar o educando e logo utilizou o Jogo 60 Segundos (jogo de encaixe que trabalha figura-fundo). Após o término deste, seguiu a atividade com o jogo de cartas de sombras do Patati-Patatá 5 . Todas as sessões eram estruturadas e repletas de atividades, assim, em cada atendimento, eram utilizadas duas ou três atividades, como na sessão de AEE descrita anteriormente. Quando as atividades eram mais simples, realizavam cerca de quatro ou cinco. Além disso, quando havia a utilização do software Coelho Sabido, a docente procurava realizar o maior número possível de atividades presentes no software.

É importante considerar que o atendimento para estes educandos deveria ser estruturado de forma a desenvolver suas habilidades e competências, não apenas uma prática com um fim em si mesma. Isto é, deveria possuir relação direta com as necessidades do educando, visto que "a educação correta consiste em despertar na criança aquilo que existe nela, ajudar para que isso se desenvolva e orientar esse desenvolvimento para algum lado". (VIGOTSKI, 2009, p.72).

${ }^{5}$ Personagens infantis 
Desse modo, quando Diana optava por um grande número de atividades para serem desenvolvidas em um curto espaço de tempo, limitava as possibilidades de desenvolvimento que poderiam ser desencadeadas caso optasse pela exploração do conteúdo, principalmente quando utilizava um método de ensino convencional para os educandos que atendia, os quais podem carecer de diferentes abordagens de ensino (GOMES; MENDES, 2010).

No caso em análise, a prática da professora envolvia excesso de atividades, geralmente, desvinculadas dos conteúdos da sala de aula comum e com enfoque exclusivo na utilização dos materiais disponíveis na SRM. Esses materiais, segundo Braun e Vianna (2011), possuem o objetivo de auxiliar no processo de ensino aprendizagem, visando desenvolver os conteúdos inerentes à sala de aula comum, ainda que de forma diferenciada, não devendo nortear exclusivamente a ação do professor do AEE. No entanto, não foi isso o constatado durante as sessões observadas.

Em diversos momentos das sessões de autoconfrontação, Diana falou sobre o educando, a forma com que o mesmo realizou a atividade fazendo uso do material e sobre como ele estava se sentindo. Esses aspectos apareceram de forma significativa na autoconfrontação 1 e também na autoconfrontação 2, conforme ilustra um dos enxertos:

Aquela da mesa por mim eu nem usava mais aquele material, mas não, eu vou refazer. Como eu vou usar aquele material? Na realidade, não é que eu usei errado. Não surtiu efeito de como manda o figurino, usar como a regra mandava usar (Autoconfrontação 2).

A professora ainda buscava desvelar o que tinha acontecido para o insucesso do jogo, inclusive, afirmou que "não surtiu o efeito de como mandava o figurino". De fato, a docente parecia se sentir impotente diante das dificuldades do educando e de suas próprias limitações. Durante as sessões, pouco intervia mediante ao fracasso do aluno e deixava que as tentativas e erros norteassem as atividades.

Gomes e Mendes (2010) fazem menção aos obstáculos existentes no ato de ensinar educandos com TEA, dando ênfase ao tipo de metodologia utilizado, visto que o método escolhido pode ser um dos motivos do fracasso da aprendizagem. Assim, o material escolhido por Diana foi foco de reflexão, justamente pelo fato de a professora ter expectativas em relação à reação do educando durante a utilização do material. Indubitavelmente, a professora depositava o sucesso da atividade no recurso que iria usar, o que não deveria ocorrer. Tal posicionamento pode ser visualizado na fala a seguir: 
$\mathrm{Na}$ realidade, aquele material, no planejamento nosso [Diana e a professora do AEE do turno vespertino] de janeiro, a gente iria abordar a questão do esquema corporal, da percepção, lateralidade, etc, mas a gente não iria abordar com aquilo, no planejamento de janeiro. A gente iria abordar com cartolina, com papel sulfite maior. Ia desenhar. Era outra abordagem, quando chegou o material a gente ficou encantada. Pronto para gente trabalhar e de uma maneira muito mais lúdica. Eu não sei se o fato da gente estar preso ao que a gente planejou não deu muito efeito, [...] eu não percebi realmente o que deu errado ali (Autoconfrontação 2).

No relato de Diana, percebe-se que houve modificação no planejamento de seu atendimento a fim de adequá-lo ao material recebido, transmitindo, assim, a ideia de que os recursos norteiam as atividades executadas na SRM. O serviço do AEE objetiva identificar as necessidades do educando e estimular suas potencialidades e compete a cada professor do AEE receber o recurso e decidir a forma de utilizá-lo, contudo, sem permitir que ele defina o tipo de atendimento a ser realizado. O educando que frequenta esse serviço precisa desenvolver várias aprendizagens para continuar usufruindo dos conhecimentos advindos da educação formal (GOMES, 2011), e atividades sem vínculo com suas necessidades não irá auxiliá-lo no acesso aos conhecimentos acadêmicos.

A busca pelo motivo do fracasso da atividade e por uma nova forma de agir foi recorrente em ambas as sessões de autoconfrontação, como também, a percepção da professora de que poderia ter realizado a atividade de forma diferente:

Eu tinha o sentimento de modificar ela toda. Não atingiu o objetivo. Não ia atingir o objetivo já no meio do caminho. [...] A partir do momento que os bonecos, que não houve um vínculo dele com os bonecos, ele não teve o interesse que eu achei que ele poderia ter. Eu guardaria e entraria noutra atividade [...] talvez eu mudasse completamente o conteúdo (Autoconfrontação1).

Diante desses aspectos, visualiza-se que, por intermédio da autoconfrontação simples, Diana revelou a necessidade de modificações em sua prática e analisou a importância de usar a flexibilidade nos momentos de insucesso das atividades. Sem dúvida, pode-se afirmar que as sessões de autoconfrontação alcançaram seu objetivo, pois foram "marcadas por muitas reflexões, análise, sugestões, dúvidas questionamentos" (SOARES; BARBOSA, 2010, p.47). Sobre isso, Diana declarou que:

É muito interessante a gente ver a gente. Eu acho que tem muitas coisas que você vê, que questiona, que eu falo aqui e depois eu fico pensando: 'poxa realmente eu devia ter feito assim, assado'. Tem muitas coisas que a gente bate (Autoconfrontação 2).

O recurso da autoconfrontação simples contribuiu para que a professora pudesse refletir sobre suas práticas por meio da autoanálise realizada utilizando imagens da sua 
própria ação docente. Com o uso deste método, a profissional teve a possibilidade de repensar sua prática e se modificar mediante as sessões reflexivas, transformando assim, sua atividade docente (DOUNIS, 2013).

Esses aspectos possibilitam considerar as questões positivas existentes na autoconfrontação no que se refere à (auto)formação dos profissionais, principalmente quando estes executam a mesma atividade por longos anos sem terem acesso à reflexão sobre sua ação.

\section{CONSIDERAÇÕES FINAIS}

A escola é um lócus privilegiado para a troca de conhecimentos devido às vivências e às diferentes ações existentes dentro dela. Ao se falar de inclusão escolar, partiu-se do pressuposto de que a escola deve possuir ações que possam contribuir para a inclusão de todos, abrangendo acesso, permanência e aprendizagem. Tais ações devem ser pensadas na pluralidade de todos os estudantes que frequentam a escola, entre eles, os estudantes com TEA, foco deste estudo.

Neste trabalho, considerou-se que o sujeito é sócio histórico, cabendo a ele e/ou seu responsável a escolha do ambiente em que deve ser escolarizado. A proposta do AEE realizado na escola regular na qual o estudante frequenta é ampla e imprescindível para a formação do sujeito que o frequenta, mas, se sua ação for negligenciada, pode ocasionar em mais um favorecedor do fracasso escolar.

Quando o AEE é limitado e/ou retrospectivo, no sentido vigotskiano, sua aprendizagem é prejudicada, dificultando o acesso ao conhecimento presente e futuro. Sendo assim, é necessário que os professores do AEE reconheçam seu papel na educação de seus educandos. Os estudantes com TEA desta pesquisa estavam nos anos iniciais da sua vida acadêmica, contudo, a forma de aprender e interagir já estava sendo construída e irá acompanhá-lo em toda a sua vida escolar.

No que diz respeito à atividade docente da professora pesquisada, verificou-se que, embora ela tivesse formação, esta não a auxiliava nas resoluções dos desafios advindos do AEE para educandos com TEA. A docente privilegiava a utilização de inúmeras atividades de cunho psicopedagógico e a utilização de software, deixando à mercê muitos dos aspectos planejados para o atendimento dos educandos. Os objetivos relacionados à comunicação, compreensão e autonomia praticamente não foram desenvolvidos ao longo das sessões, de modo que o prescrito no plano do AEE não se materializou nos atendimentos observados. 
É imprescindível refletir que o AEE construído pela professora necessitava materializar-se nas rotinas dos educandos, possibilitando a estes, condições de acesso, participação e aprendizagem em outros ambientes escolares. O AEE deve, portanto, estimular o educando a desenvolver suas potencialidades individuais, permitindo que o mesmo derrubar derrube as barreiras que dificultam seu processo de aprendizagem.

Em relação às sessões de autoconfrontação, estas mostraram que é possível haver uma reflexão sobre a atividade docente por parte do profissional participante. A abordagem junto à docente possibilitou que ela percebesse, em diversos momentos, outras formas de facilitar o acesso ao conteúdo para o educando e possíveis necessidades de tomadas decisões. Assim, a professora passou a enxergar aspectos antes não considerados, adquirindo assim um novo conhecimento sobre si e sobre sua atividade.

Vale ressaltar que se faz necessário realizar outras pesquisas, a fim de se ampliar o conhecimento acerca da atividade docente dos professores do AEE, uma vez que esta função é relativamente recente. Nesse sentido, há que se pensar em uma formação condizente com as necessidades desses profissionais, de modo a contemplar conhecimentos que contribuirão para o seu desenvolvimento profissional.

\section{REFERÊNCIAS}

APA (American Psychiatric Association). Transtornos mentais. DSM-V. In: . Manual diagnóstico e estatísticos de transtornos mentais. 5. ed. Porto

Alegre, RS: Artmed, 2014. p. 50-59.

BARBOSA, M. O.; FUMES, N. L. F.O Atendimento Educacional Especializado (AEE) e o educando com autismo: a voz dos professores da sala de recurso multifuncionais. In: V Congresso Brasileiro de Educação Especial (CBEE). Anais... São Carlos, SP. 2012. p. 24162430 .

BARDIN, L. Análise de conteúdo. 4. ed. Lisboa: edições70, 2009.

BELISÁRIO FILHO, J. F. CUNHA, P. A Educação Especial na Perspectiva da Inclusão Escolar: transtornos globais do desenvolvimento. Brasília: Ministério da Educação, Secretaria de Educação Especial, 2010.

BRAUN, P.; VIANNA, M. M. Atendimento educacional especial, sala de recursos multifuncionais e plano individualizado: desdobramentos de uma fazer pedagógico. In: PLETSCH, M. D.; DAMASCENO, A. (Org). Educação Especial e inclusão escolar: reflexões sobre o fazer pedagógico. Rio de Janeiro: Seropédia - Ed. da UFRRJ, 2011.p. 345-359. 
BRASIL. Ministério da Educação. Lei de Diretrizes e Bases da Educação Nacional, LDB 9.394, de 20 de dezembro de 1996.

. Resolução 2/2001. Institui Diretrizes Nacionais para a Educação Especial na Educação Básica.do Conselho Nacional de Educação/Câmara de Educação Básica (CNE/CEB), 2001.

Política Nacional de Educação Especial na Perspectiva da educação Inclusiva. Brasília, MEC/SEESP, 2008.

Resolução $n^{o}$ 4, de 2 de outubro de 2009. Institui Diretrizes Operacionais para o Atendimento Educacional Especializado na Educação Básica, modalidade Educação Especial. 2009.

Decreto $n^{\circ} 7.611$, de 17 de novembro de 2011. Dispõe sobre a educação especial, o atendimento educacional especializado e dá outras providências. 2011.

Lei $n^{\circ}$ 12.764, de 27 de dezembro de 2012. Institui a Política Nacional de Proteção dos Direitos da Pessoa com Transtorno do Espectro Autista, 2012.

Nota técnica $n^{\circ} 24$. Orientação aos Sistemas de Ensino para a implementação da Lei $\mathrm{n}^{\circ}$ 12.764/2012MEC / SECADI / DPEE. 2013.

CINTRA, R. C. G. G.; JESUINO, M. S.; PROENÇA, M. A. M. A prática pedagógica no Atendimento Educacional Especializado ao educando com autismo: o estado do conhecimento realizado no banco de teses da Capes e Scielo. Anais do IV Congresso Brasileiro de Educação Especial (CBEE)... São Carlos, 2010.p. 1-12.

CHIOTE, F. A. B. Inclusão da criança com autismo na educação infantil: trabalhando a mediação pedagógica. Rio de Janeiro, RJ: Wak editora, 2013.

CLOT, Y. A função psicológica do trabalho. 2. ed. Petrópolis, RJ: Editora Vozes, 2007.

CRESWELL, J. W. Projeto de pesquisa: métodos qualitativo, quantitativo e misto. Trad. Magda Lopes. 3. ed. Porto Alegre, RS: Artmed, 2010.

DOUNIS, A. B. Atividade Docente e Inclusão: as mediações da Consultoria Colaborativa. 2013. 232f. Dissertação. (Mestrado em Educação Brasileira) - Programa de pós-graduação em Educação - Universidade Federal de Alagoas, Maceió/AL, 2013.

ESTEVES, M. Análise de conteúdo In: LIMA, J. Á.; PACHECO, J. A. Fazer investigação: contributos para a elaboração de dissertações e teses. Porto, Portugal: Porto Editora, 2006.p. 31- 42 .

FLICK, U. Introdução à pesquisa qualitativa. 3. ed. Porto Alegre, RS: Bookman, 2009.

FUMES, N. L. F.; OLIVEIRA, C. V. Diagnóstico das salas de recursos multifuncionais da rede municipal de educação de Maceió/Alagoas. In: V CONGRESSO BRASILEIRO DE 
EDUCAÇÃO ESPECIAL. Universidade Federal de São Carlos, São Carlos. Anais do V Congresso Brasileiro de Educação Especial (CBEE)..., São Carlos- SP. 2012. p.1-15.

GARCIA, R. M. C. Política de educação especial na perspectiva inclusiva e a formação docente no Brasil. Revista Brasileira de Educação, V. 18, n. 52. p. 101-239, jan.-mar., 2013.

GLAT, R.; PLETSCH, M. D. Inclusão escolar de alunos com necessidades especiais. 2. ed. Rio de Janeiro, RJ: EdURJ, 2012.

GOMES, C. G. S. Aprendizagem relacional, comportamento simbólico e ensino de leitura a pessoas com transtornos do espectro do autismo. Tese (Doutorado) - Programa de pósgraduação em Educação Especial. São Carlos: UFSCar, 2011.

GOMES, C. G. S.; MENDES, E. G. Escolarização inclusiva de alunos com autismo em Belo Horizonte. Revista Brasileira de Educação Especial, v. 16, n. 3. p. 375-396, 2010.

MENDES, E. G.; MALHEIRO, C. A. L. Salas de recursos multifuncionais: é possível um serviço "tamanho único" de atendimento educacional especializado? In: MIRANDA, T. G.; GALVÃO FILHO, T. A. O professor e a educação inclusiva: formação, práticas e lugares. Salvador: EDUFBA, 2012. p.349-366.

MILANESI, J. B. Organização e funcionamento das salas de recursos multifuncionais em um município paulista. 2012. 183f. Dissertação (Mestrado) - Programa de pós-graduação em Educação Especial. Universidade Federal de São Carlos, São Carlos: UFSCar, 2012.

MURTA, A. M. G. Da atividade prescrita ao real da atividade: análise da atividade docente em uma escola regular, sob a perspectiva da psicologia sócio-histórica e da clínica da atividade. 2008. 233f. Tese de doutorado. Programa de Psicologia da Educação. Pontifícia Universidade Católica de são Paulo- PUC, São Paulo, 2008.

ORRÚ, S. E. Autismo, linguagem e educação: interação social no cotidiano escolar. 3 ed. Rio de Janeiro: Wak Ed., 2012.

SCHWARTZMAN, J. S. Transtornos do espectro do autismo: conceitos e generalidades. In: SCHWARTZMAN, J. S.; ARAÚJO, C. A. Transtornos do Espectro do autismo-TEA. São Paulo: Memnon, 2011. p. 37- 42.

SOARES, J. R.; BARBOSA, S. M. C. O movimento do sujeito na pesquisa qualitativa de autoconfrontação simples e cruzada. In: MAZZOTTI, A. J.; FUMES, N. L. F.; AGUIAR, W. M. J. (Org.). Estudos sobre a atividade docente: aspectos teóricos e metodológicos em questão. São Paulo: EDUC; EDUFAL, 2010.p. 32-50.

TARTUCI, D.; SILVA, M. R.; FREITAS, A. O. A formação dos professores do atendimento educacional especializado e a formação do professor de apoio à inclusão em Goiás: uma análise da legislação. In: I SIMPÓSIO INTERNACIONAL DE ESTUDOS SOBRE A DEFICIÊNCIA. Anais do... - SEDPcD/Diversitas/USP Legal - São Paulo, junho/2013. 
VASQUES, C. K. Alice na biblioteca mágica: uma leitura sobre o diagnóstico e a escolarização de crianças com autismo e psicose infantil. 2008. 195 f. Tese (Doutorado) - Programa de PósGraduação em Educação, Faculdade de Educação, Universidade Federal do Rio Grande do Sul, Porto Alegre, 2008.

VIGOTSKI, L. S. Imaginação e criação na infância: ensaio psicológico. Trad. Ana Luiza Smolka. São Paulo, SP: Ática, 1930/2009.

YIN, R. K. Estudo de caso: planejamento e métodos; trad. Ana Thorell. 4. ed. Porto Alegre, RS: Bookman, 2010. 